University of Nebraska - Lincoln

DigitalCommons@University of Nebraska - Lincoln

$12-2011$

\title{
Monascus pigment production by solid-state fermentation with corn cob substrate
}

\author{
Palanivel Velmurugan \\ Chonbuk National University, Korea \\ Hyun Hur \\ Korea Prime Pharma. Co. \\ Vellingiri Balachandar \\ Bharathiar University, Coimbatore, Tamil Nadu \\ Seralathan Kamala-Kannan \\ Chonbuk National University, Korea \\ Kui-Jae Lee \\ Chonbuk National University, Korea \\ See next page for additional authors
}

Follow this and additional works at: https://digitalcommons.unl.edu/natrespapers

Velmurugan, Palanivel; Hur, Hyun; Balachandar, Vellingiri; Kamala-Kannan, Seralathan; Lee, Kui-Jae; Lee, Sang-Myung; Chae, Jong-Chan; Shea, Patrick; and Oh, Byung-Taek, "Monascus pigment production by solid-state fermentation with corn cob substrate" (2011). Papers in Natural Resources. 378.

https://digitalcommons.unl.edu/natrespapers/378

This Article is brought to you for free and open access by the Natural Resources, School of at DigitalCommons@University of Nebraska - Lincoln. It has been accepted for inclusion in Papers in Natural Resources by an authorized administrator of DigitalCommons@University of Nebraska - Lincoln. 


\section{Authors}

Palanivel Velmurugan, Hyun Hur, Vellingiri Balachandar, Seralathan Kamala-Kannan, Kui-Jae Lee, SangMyung Lee, Jong-Chan Chae, Patrick Shea, and Byung-Taek Oh 


\title{
Monascus pigment production by solid-state fermentation with corn cob substrate
}

\author{
Palanivel Velmurugan, ${ }^{1}$ Hyun Hur, ${ }^{2}$ Vellingiri Balachandar, ${ }^{3}$ \\ Seralathan Kamala-Kannan, ${ }^{1}$ Kui-Jae Lee, ${ }^{1,}{ }^{4}$ Sang-Myung Lee, ${ }^{1}$ \\ Jong-Chan Chae, ${ }^{1}$ Patrick J. Shea, ${ }^{5}$ and Byung-Taek $\mathrm{Oh}^{1,4}$
}

1. Division of Biotechnology, Advanced Institute of Environment and Bioscience, College of Environmental and

Bioresource Sciences, Chonbuk National University, Iksan, Jeonbuk 570-752, South Korea

2. Korea Prime Pharma. Co., Ltd, Wanju, Jeonbuk 565-902, South Korea

3. Department of Zoology, Division of Human Genetics, Bharathiar University, Coimbatore, Tamil Nadu 641-046, India

4. Plant Medical Research Center, College of Agriculture and Life Science, Chonbuk National University,

Jeonju, Jeonbuk 561-756, South Korea

5. School of Natural Resources, University of Nebraska-Lincoln, Lincoln, NE 68583-0817, USA

Corresponding author - B.-T. Oh, Division of Biotechnology, Advanced Institute of Environment and Bioscience, College of Environmental and Bioresource Sciences, Chonbuk National University, Iksan 570-752, South Korea; tel 8263850 0838, fax 8263850 0834, email btoh@jbnu.ac.kr

Palanivel Velmurugan and Hyun Hur made equal contributions to this work and should be considered co-first authors.

\begin{abstract}
Natural pigments are an important alternative to potentially harmful synthetic dyes. We investigated the feasibility of corn cob powder as a substrate for production of pigments by Monascus purpureus KACC 42430 in solid-state fermentation. A pigment yield of 25.42 OD Units/gram of dry fermented substrate was achieved with corn cob powder and optimized process parameters, including $60 \%(\mathrm{w} / \mathrm{w})$ initial moisture content, incubation at $30^{\circ} \mathrm{C}$, inoculation with $4 \mathrm{~mL}$ of spores/gram of dry substrate, and an incubation period of 7 days. Pigment yield using corn cobs greatly exceeded those of most other agricultural waste substrates. The pigments were stable at acidic $\mathrm{pH}$, high temperatures, and in salt solutions; all important considerations for industrial applications. Our results indicate the viability of corn cob substrate in combination with M. purpureus for industrial applications.
\end{abstract}

Keywords: Corn cob substrate, Monascus purpureus, Natural pigments, Solid-state fermentation, $N$-Acetyl glucosamine

Natural dyes were the main colorants for textiles through the 19th century (1). Since then synthetics have almost completely replaced natural dyes. The wide range of available colors, greater reproducibility, improved quality of dyeing, and economic benefits of synthetic dyes are highly desirable. However, it is well known that some of the synthetic dyes are environmental toxins and negatively impact ecosystems. Recent studies reported that $10-35 \%$ of these dyes are lost in wastewater during the dyeing process $(2,3)$. Due to serious environmental pollution concerns, textile industries are facing extensive problems and several have banned various synthetic coloring agents. Consequently there is a growing demand for ecofriendly, non-toxic colorants for industrial applications.

Natural dyes or pigments are an important alternative to potetially harmful synthetics (3). Numerous studies report that microorganisms of the genus Monascus produce red pigments, which are used as coloring agents in food and textiles (4-6). Moreover, in several Asian countries, Monascus species are grown on rice grains, and used for coloring some foods (7), increasing the demand for the highly safe pigments. However, the high cost of the current liquid culture-based fermentation technology has limited the industrial use of Monascus pigments. Thus, there is a growing need for low cost production of natural pigments or coloring agents.
Solid state fermentation (SSF) has emerged as an effective alternative for liquid, culture-based fermentation technology. The substrates used in SSF supply the basic nutrients to the microorganisms and serve as an anchor for the cells (8). Interestingly, recent studies report that SSF provides a more adequate habitat for fungi, resulting in high pigment production in a relatively low-cost process when agro-industrial wastes are used as substrate. Agro-industrial wastes such as rice bran, wheat bran, coconut oil cake, sesame oil cake, palm kernel cake, groundnut oil cake, cassava powder, spent brewing grain, and jackfruit seed powder have been screened to select the best substrate for pigment production (8). However, to our knowledge no effort has been made to utilize the corn cob for this purpose. The cob is the central core of the maize (Zea mays ssp. mays L.) seed head or "ear." When harvesting corn the cob is collected as part of the ear, leaving the corn stover in the field. Corn cobs are an important source of furfural, an aromatic aldehyde used in a wide variety of industrial processes. Although of little nutrititional value, corn cobs can be used as fiber in ruminant fodder. For many years corn cobs have also been made into charcoal. The corn cob contains considerable amounts of polysaccharides (such as cellulose and hemicelluloses), which promote fungal growth and thereby increase pigment yield. Corn cobs are a highly economical 
substrate for SSF, compared to other substrate previously used for pigment production. The objective of our study was to develop a fermentation process for production of Monascus pigments employing SSF using corn cobs. We optimized key parameters to maximize pigment production.

\section{Materials and methods}

Monascus purpureus culture - Monascus purpureus KACC 42430 was acquired from the Korea Agriculture Culture Collection (KACC). The culture was maintained on potato dextrose agar (Difco, Paris, France), preserved at $4^{\circ} \mathrm{C}$, and sub-cultured every three weeks.

Inoculum preparation - Ten milliliters of sterile distilled water was added to fully sporulated ( 6 to 8 day-old) agar slope culture and the spores were scraped from the agar plates under aseptic conditions. The spore suspension was used as the inoculum.

Substrate and solid-state fermentation - Corn cobs were obtained from local agricultural fields around Iksan, South Korea. Cobs were washed thoroughly and dried in sunlight, then ground to $2 \mathrm{~mm}$ particle size using a sterile blender. The prepared material was soaked in deionized water at $80^{\circ} \mathrm{C}$ for $12-48 \mathrm{~h}$ to increase porosity and bulk density. Then the material was pressed to remove the water and dried in the shade. Five grams of the dry substrate was placed in a $250 \mathrm{~mL}$ Erlenmeyer flask and a nutrient salt solution $(2 \mathrm{~mL})$ containing $(\mathrm{g} / \mathrm{L})$ : $\mathrm{KH}_{2} \mathrm{PO}_{4}, 2 ; \mathrm{NH}_{4} \mathrm{NO}_{3}, 5 ; \mathrm{NaCl}, 1$; and $\mathrm{MgSO}_{4} \cdot 7 \mathrm{H}_{2} \mathrm{O}, 1(9,10)$ was added by adjusting different $\mathrm{pH}$ ( $\mathrm{pH} 1-8$ ). Initial moisture content was adjusted to $50 \%$ (w/w) with distilled water. Flask contents were mixed thoroughly, autoclaved at $121^{\circ} \mathrm{C}$ for $20 \mathrm{~min}$, and cooled to room temperature. The flask was inoculated with the M. purpureus KACC 42430 spore suspension $\left(6 \times 10^{5}\right.$ spores $\left./ \mathrm{mL}\right)$ and incubated at $30^{\circ} \mathrm{C}$ and $50 \%$ humidity for $7 \mathrm{~d}$. Unless otherwise indicated, these conditions were maintained throughout the experiment. All experiments were conducted in triplicate and means \pm standard deviations are reported.

Biomass estimation - Total fungal biomass was determined by measuring the $N$-acetylglucosamine released by acid hydrolysis of the chitin present in the fungal cell walls $(10,11)$. In brief, $0.5 \mathrm{~g}$ of dry fermented corn cob powder was mixed with $1 \mathrm{~mL}$ of concentrated $\mathrm{H}_{2} \mathrm{SO}_{4}$. Acetyl acetone reagent $(1 \mathrm{~mL})$ was added to the mixture, which was then placed in a boiling water bath for $20 \mathrm{~min}$. After cooling, $6 \mathrm{~mL}$ of ethanol was added, followed by $1 \mathrm{~mL}$ of Ehrlich reagent (Sigma-Aldrich, Milwaukee, WI, USA) and incubated at $65^{\circ} \mathrm{C}$ for $10 \mathrm{~min}$. After cooling to room temperature, optical density (OD) was measured at $530 \mathrm{~nm}$ against the reagent blank using $N$-acetylglucosamine (Sigma-Aldrich) as the external standard.

Pigment extraction and quantification - After $7 \mathrm{~d}$ of incubation, the substrate was dried on aluminum foil at room temperature and ground to a fine powder using a sterile household grinder. Pigment was extracted following the procedure of Babitha et al. (8). In brief, fermented solid substrate was extracted with $5 \mathrm{~mL}$ of $90 \%$ methanol per gram of dry fermented substrate (gdfs). The mixture was placed on a rotary shaker at $200 \mathrm{rpm}$ for $1 \mathrm{~h}$, allowed to stand for $15 \mathrm{~min}$, and filtered through Whatman \#1 filter paper.

Following the method of Tseng et al. (12), extracellular pigment was quantified by measuring OD at 412 and $500 \mathrm{~nm}$, representing yellow and red pigment production, respectively and pigment yield was expressed as OD/gdfs. Absorbance was also measured for pigment extract (13-15).

Substrate preparation variables - To study the effect of soaking on pigment production, flasks were placed on a rotary shaker at $100 \mathrm{rpm}$ for $0,12,24$, and $48 \mathrm{~h}$ at $80^{\circ} \mathrm{C}$. The following parameters were also evaluated: incubation time (12 to $264 \mathrm{~h}$ ), moisture content of the substrate (adjusted to $40 \%, 50 \%$, and $60 \%$ w/w with distilled water), temperature $\left(20^{\circ} \mathrm{C}, 30^{\circ} \mathrm{C}, 40^{\circ} \mathrm{C}, 50^{\circ} \mathrm{C}\right.$, and $60^{\circ} \mathrm{C}$; for fungal growth and pigment production), inoculum size, and substrate $\mathrm{pH}$ (by adjusting the salt solution $\mathrm{pH}$ after autoclaving). Growth kinetics was estimated from temporal changes in biomass. Pigment production was determined spectrophotometrically, as previously described.

Pigment stability - Pigment stability was determined using the method of Srivastava et al. (16) and Perumal et al. (17). Briefly, glass test tubes containing $10 \mathrm{~mL}$ of the fungal pigment were incubated in a water bath at $40^{\circ} \mathrm{C}, 50^{\circ} \mathrm{C}, 60^{\circ} \mathrm{C}$, $70^{\circ} \mathrm{C}, 80^{\circ} \mathrm{C}, 90^{\circ} \mathrm{C}$, and $100^{\circ} \mathrm{C}$ for $10 \mathrm{~min}$. After cooling to room temperature, absorbance was measured using a UV-visible spectrophotometer and percent stability was calculated. Extracts $(10 \mathrm{~mL})$ in another set of tubes were adjusted to $\mathrm{pH} 2$, $4,6,8,10,12$ or 14 , mixed for $10 \mathrm{~min}$, and absorbance measured. Tubes containing $10 \mathrm{~mL}$ of extract also were incubated under stress conditions, including $12 \mathrm{~h}$ in a hot air oven at $90^{\circ} \mathrm{C}, 2 \mathrm{~h}$ in sunlight, and steaming at $834 \mathrm{kPa}$ for $20 \mathrm{~min}$. Another set of tubes containing $10 \mathrm{~mL}$ of the fungal pigment extract were incubated under UV light for $12 \mathrm{~h}$. Test tubes containing $10 \mathrm{~mL}$ of extract were amended with $0.1 \%, 0.2 \%, 0.3 \%, 0.4 \%, 0.5 \%, 0.6 \%, 0.7 \%, 0.8 \%, 0.9 \%$, and $1 \%(\mathrm{v} / \mathrm{v})$ salt solution $\left(\mathrm{NaCl}\right.$ and $\left.\mathrm{NH}_{4} \mathrm{Cl}\right)$ and kept in a warm water bath for $1 \mathrm{~h}$ to determine stability in textile dyeing. Stability $(\% E)$ was calculated:

$$
\% E=\left[\left(A_{0}-A_{1}\right)\right] \times 100 / 10
$$

where $A_{0}$ is pigment absorbance before treatment and $A_{1}$ is absorbance after treatment. Absorbance was measured spectrophotometrically at $500 \mathrm{~nm}$ of the pigment.

\section{Results and discussion}

General observations - The applicability of corn cob waste as a substrate for pigment production was evaluated using $M$. purpureus KACC 42430 . Soaking the corn cob powder at $80^{\circ} \mathrm{C}$ for $48 \mathrm{~h}$ resulted in greater pigment production (Figure 1). Fermentation yielded a highest red pigment concentration (25.42 OD Units/gdfs) using corn cob compared to other agro industrial wastes such as coconut oil cake (0.118 OD Units/gdfs), groundnut oil cake $(0.150$ OD Units/gdfs), sesame oil cake (0.375 OD Units/gdfs), tamarind seed powder (1.146 OD Units/gdfs), cassava flour (1.458 OD Units/gdfs), wheat bran (3.525 OD Units/gdfs), spent brewing grain (4.356 OD Units/gdfs), palm kernel cake (7.650 OD Units/ gdfs), and jackfruit seed powder (12.113 OD Units/gdfs) (6). Spectral analysis indicated maximum absorbance at $490 \mathrm{~nm}$ (data not shown), confirming red pigment production by M. purpureus KACC 42430. Our results are consistent with studies reporting greater pigment production by $M$. purpureus LPB 97 using jackfruit seed powder as substrate (9) and by $M$. purpureus CMU001 using inexpensive agricultural products and residues (10). Corn cobs contain $32.3-45.6 \%$ cellulose and $39.8 \%$ hemicelluloses (primarily composed of pentosan and 6.7-13.9\% lignin). Cellulose is a polysaccharide of glucose units that serve as the main structural component of cob cell walls. Hemicellulose is a less complex polysaccharide that can more easily be broken down to simple monosaccharides. The extracellular hydrolytic enzymes of $M$. purpureus degrade the complex polysaccharides (cellulose and hemicellulose) into simple molecules and thereby increase the bioavailability of the sugars. The increased bioavailability of sugars directly enhances the growth rate of fungi as well as pigment production.

a.

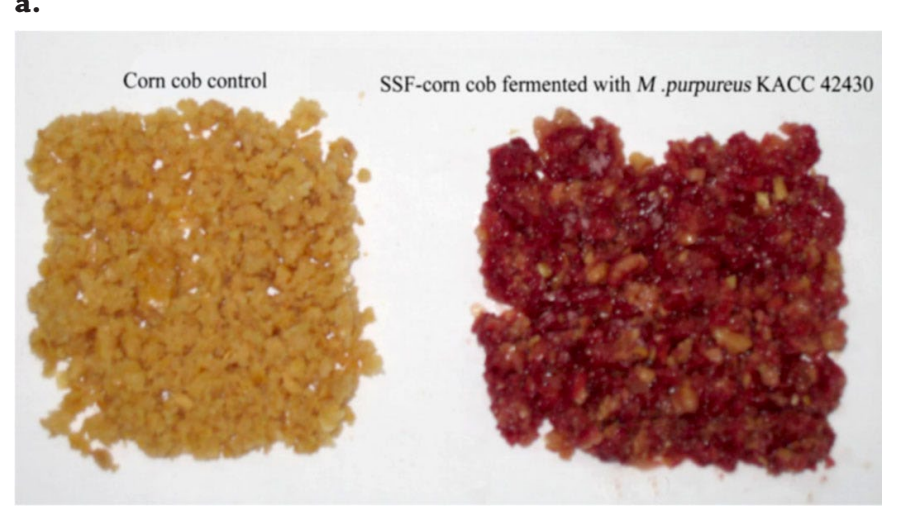

b.

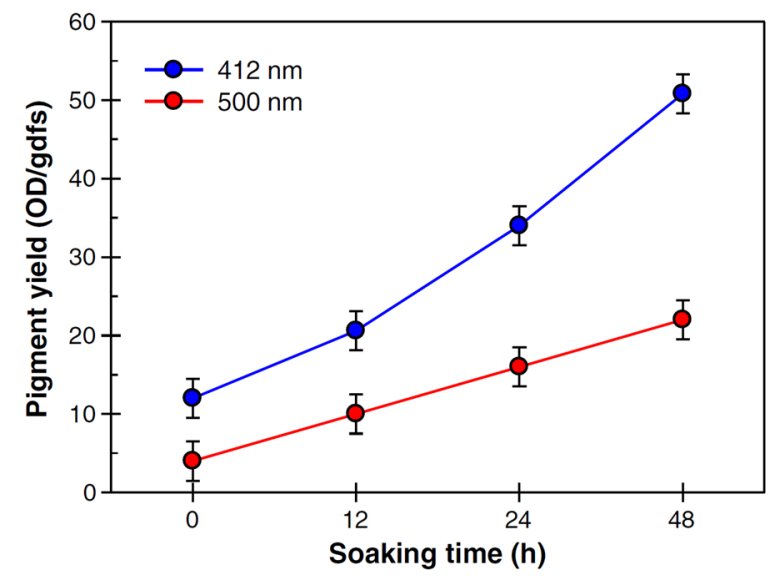

Figure I. (a) Solid state fermentation (7 days incubation at $30^{\circ} \mathrm{C}$ with $60 \%$ (w/w) moisture content) of non-fermented and fermented corn cob. (b) Pigment yield $(412$ and $500 \mathrm{~nm})$ in solid state fermentation by M. purpureus KACC 42430 in response to substrate soaking time. 
Substrate $\mathbf{p H}-$ Substrate $\mathrm{pH}$ is one of the most important factors determining microbial growth and metabolic activity in SSF. M. purpureus biomass and pigment yield were determined at different initial substrate $\mathrm{pH}$ levels (Figure 2). Fungal growth was completely inhibited at $\mathrm{pH} 1$ and 2. However, at $\mathrm{pH} 3.0$ and 4.0, the $\bigotimes_{\max }$ shifted to 480 and $390 \mathrm{~nm}$, respectively. These observations are consistent with Babitha et al. (8), who reported a similar $\nabla_{\max }$ shift for Monascus pigments at $\mathrm{pH}$ 3. Yongsmith et al. (18) reported that a lower substrate $\mathrm{pH}$ promotes synthesis of yellow pigments, whereas a higher $\mathrm{pH}$ results in red pigments. In our study, yield differed between $\mathrm{pH} 5$ and 6; yellow pigment (26.42 OD Units/gdfs at $412 \mathrm{~nm}$ ) production was maximal at $\mathrm{pH} 6$ and red pigment (24.18 OD Units/gdfs at $500 \mathrm{~nm}$ ) was maximal at $\mathrm{pH}$ 5. Pigment production was reduced at $\mathrm{pH} 7$ and 8 , and was completely inhibited with further increases in $\mathrm{pH}$. These results are consistent with Babitha et al. (8), who reported maximum pigment production by $M$. purpureus at $\mathrm{pH} 4.5$ to 7.5 , while using jack fruit seed as substrate in solid state fermentation. $\mathrm{N}$-acetyl glucosamine concentration was greatest at $\mathrm{pH} 5$ (270 mg/gdfs) followed by $\mathrm{pH} 6$, indicating maximum growth and pigment production.

Temperature - Temperature is one of the most critical factors in SSF based on fungi cultures. Because of the mesophilic nature of $M$. purpureus, maximum growth and pigment production was obtained at $30^{\circ} \mathrm{C}$ (Figure 3). Results are in agreement with Domsch et al. (19) and Babitha et al. (8), who reported an optimum temperature of $30^{\circ} \mathrm{C}$ to $37^{\circ} \mathrm{C}$ for Monascus sp. An interesting observation is that the maximum absorbance shifted to $390 \mathrm{~nm}$ (which corresponds to yellow pigments) when the temperature was above $30^{\circ} \mathrm{C}$. Babitha et al. (8) and Carvalho et al. (20) similarly reported shifts in absorption maxima at different incubation temperatures. Maximum pigment production occurred at $30^{\circ} \mathrm{C}(41.14$ OD Units yellow pigment/gdfs at $412 \mathrm{~nm}$ and 25.52 OD Units red pigment/gdfs at $500 \mathrm{~nm}$ ); production decreased drastically at higher temperatures. At $30^{\circ} \mathrm{C}$, maximum $\mathrm{N}$-acetyl glucosamine concentration was $160 \mathrm{mg} /$ gdfs.

Inoculum size - Numerous studies have shown the large influence of inoculum size on product yield in SSF and our observation was similar. Inoculating with $4 \mathrm{~mL}$ of spores/gram of initial dried substrate (gds) maximized yellow pigment yield (28.12 OD Units/gds at $412 \mathrm{~nm}$ ), followed by red pigment (22.14 OD Units/ gdfs at $500 \mathrm{~nm}$ ), with a biomass of $220 \mathrm{mg} / \mathrm{gds}$ (Figure 4). These results are in agreement with previous studies $(8,21,22)$. Too little inoculum resulted in insufficient biomass and smaller amounts of product, whereas too much inoculum produced excessive biomass and depleted the nutrients required for pigment formation (8).

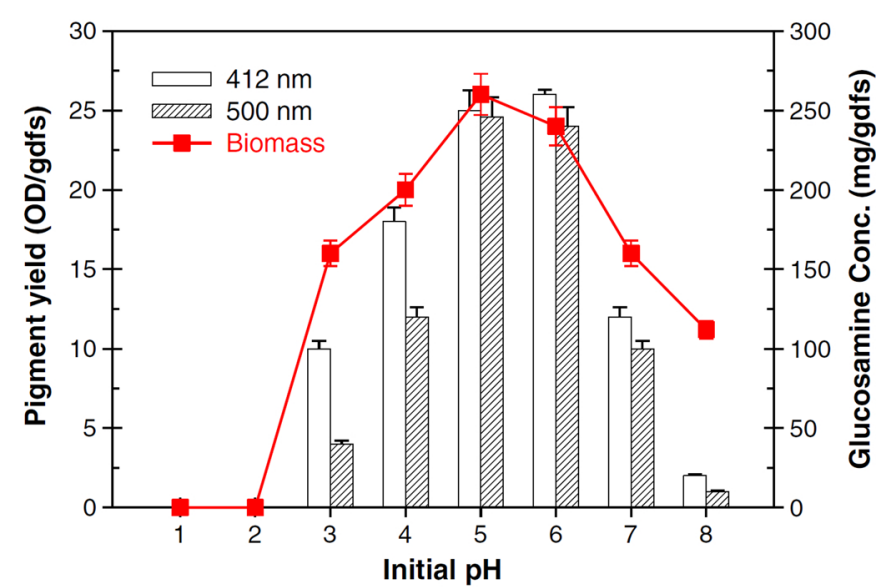

Figure 2. Growth (glucosamine concentration) and pigment yield (optical density 412 and $500 \mathrm{~nm}$ ) of $M$. purpureus in solid state fermentation at different initial substrate $\mathrm{pH}$, incubation temperature, inoculum size, incubation period and initial moisture content.

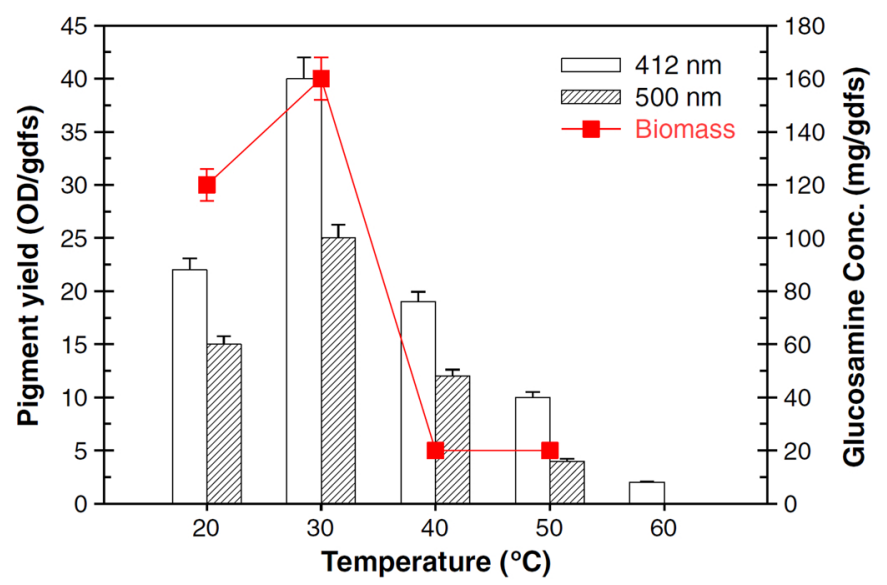

Figure 3. Growth (glucosamine concentration) and pigment yield (optical density 412 and $500 \mathrm{~nm}$ ) of $M$. purpureus in solid state fermentation at different incubation temperatures, inoculum size, incubation period and initial moisture content.

Incubation time - The amount of pigment produced varied with incubation time (Figure 5). Maximum yellow and red pigment production was obtained at $168 \mathrm{~h}$ (33.42 OD Units/gdfs at $412 \mathrm{~nm}$ and 15.28 OD Units/gdfs at $500 \mathrm{~nm}$, respectively), with a biomass of $199 \mathrm{mg} / \mathrm{gdfs}$ at 144 and $168 \mathrm{~h}$. Production decreased from 192 to $264 \mathrm{~h}$, likely due to the decline phase of the fungus.

Moisture content - Substrate moisture content plays a key role in fungal growth, enzyme activity, and metabolite production in SSF $(18,23-25)$. The effect of substrate moisture content on red pigment production and biomass was presented in Figure 6. Yellow and red pigment production was maximal at $60 \%$ moisture content (18.92 OD Units/gdfs at $412 \mathrm{~nm}$ and 14.26 OD Units/gdfs at $500 \mathrm{~nm}$, respectively). This can be attributed to effective utilization of sugars in the substrate. Results are consistent with Yongsmith et al. (18), who reported maximum glucoamylase activity and pigment production by Monascus sp. KB9 at 60\% moisture. Pigment yield decreased above or below $60 \%$ moisture. The lower yield at high moisture content is due to agglomeration of substrate, reducing oxygen supply for $M$. purpureus. The decrease in pigment production at low moisture content is a result of low nutrient availability due to reduced nutrient salt dissolution, as well as less efficient heat exchange and oxygen transfer $(8,26)$. Results are similar to those of Johns and Stuart (15) and Babitha et al. (8), who reported reduced pigmentation at substrate moisture content below $40 \%$.

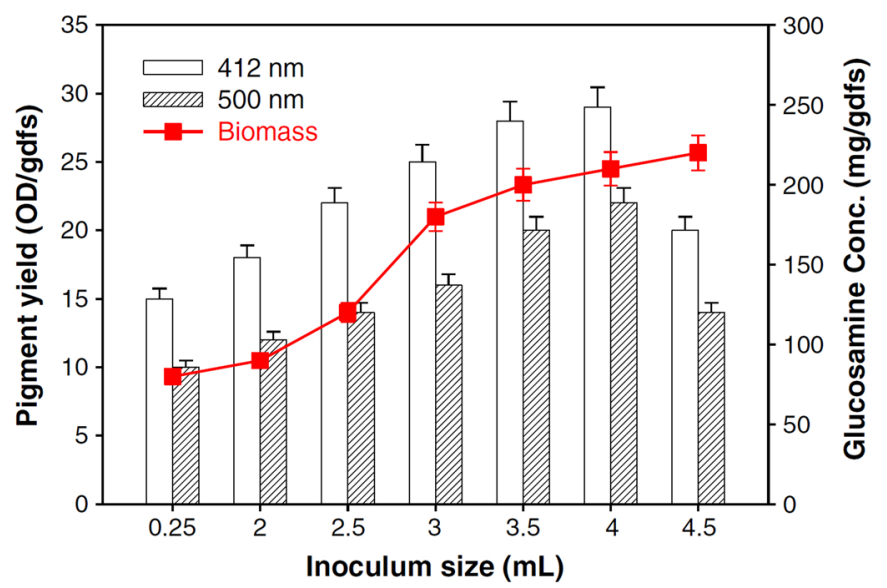

Figure 4. Growth (glucosamine concentration) and pigment yield (optical density 412 and $500 \mathrm{~nm}$ ) of $M$. purpureus in solid state fermentation in response to inoculum size, incubation period and initial moisture content. 


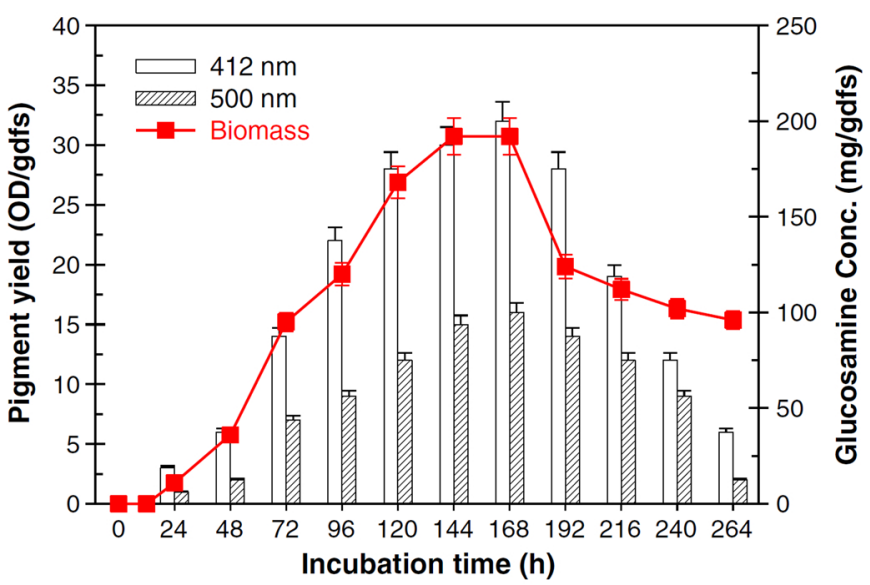

Figure 5. Growth (glucosamine concentration) and pigment yield (optical density 412 and $500 \mathrm{~nm}$ ) of M. purpureus in solid state fermentation in response to incubation period and initial moisture content.

Pigment stability - The extracted Monascus pigments were subjected to various physical and chemical treatments and results are presented in Table 1 . The pigment is soluble in water and color was red at $500 \mathrm{~nm}$. The pigment powder is essentially non-hygroscopic in nature and the Munsell hue test indicated a red color. The original color was retained at $\mathrm{pH} \mathrm{5,6}$ and 7. Under more acidic conditions ( $\mathrm{pH} 1-4)$ the pigment lost its color and precipitated at the bottom of the tubes; the color changed at alkaline $\mathrm{pH}(\mathrm{pH} \mathrm{8-14).}$ A brown shade was observed at $\mathrm{pH} 8$, orange at $\mathrm{pH} \mathrm{9}$, yellow at $\mathrm{pH}$ 10 , and pale red at $\mathrm{pH} 14$. The color change can be attributed to protonation/dissociation below/above the molecular dissociation constant of the pigment molecules. The presence/absence of color for a specific pigment is a function of $\mathrm{pH}$ due to ionization of aromatic $-\mathrm{OH}$ groups and tautomerism of $-\mathrm{O}(-)$ with $=\mathrm{O}$. Changes in the relative proportions of dissociated/undissociated molecules (with respective colors) would produce the resulting coloration, such as orange at $\mathrm{pH} 9$, yellow at $\mathrm{pH} 10$, and red at 14 .

Thermostability of the pigment was determined at $40^{\circ} \mathrm{C}$ to $100^{\circ} \mathrm{C}$ (Table 1). The constancy of absorbance at $500 \mathrm{~nm}$ indicates thermostability. Color was also retained when the pigments were subjected to steaming and sunlight exposures. The pigment was stable in solution containing up to $0.5 \%(\mathrm{w} / \mathrm{v})$ sodium chloride and ammonium chloride. However, pigment color changed to brown during $12 \mathrm{~h}$ of exposure to hot air.

Table I. Red pigment properties and stability after various treatments.

\begin{tabular}{|c|c|c|c|}
\hline Parameter & Properties & s Observed stability & Relative stability (\%) \\
\hline Water solubility & Soluble & - & - \\
\hline Color $\left(\lambda_{\max }\right)$ & $500 \mathrm{~nm}$ & - & - \\
\hline Hygroscopy & Little & - & - \\
\hline Hue & Dark red & - & - \\
\hline $\mathrm{pH} 2-14(10 \mathrm{~min})$ & - & $\mathrm{pH} 4,5,6,7$ & 99.0 \\
\hline Dry heat $\left(60^{\circ} \mathrm{C}\right.$ for $12 \mathrm{I}$ & h) - & - & 86.2 \\
\hline $121^{\circ} \mathrm{C}(20 \mathrm{~min})$ & - & - & 95.9 \\
\hline UV light (12 h) & - & - & 99.2 \\
\hline Sun light (2 h) & - & - & 99.4 \\
\hline $\begin{array}{l}\text { Sodium chloride } \\
\qquad(0.1-1 \% \mathrm{w} / \mathrm{v}, \mathrm{pH} 7.0,1\end{array}$ & I h) & $0.1,0.2,0.3,0.4,0.5,0.6 \%$ & 96.1 \\
\hline $\begin{array}{l}\text { Aluminum chloride } \\
\qquad(0.1-1 \% \mathrm{w} / \mathrm{v}, \mathrm{pH} 7.0,1\end{array}$ & $\mid \mathrm{h})^{-}$ & $0.1,0.2,0.5 \%$ & 90.2 \\
\hline
\end{tabular}

-, Not applicable

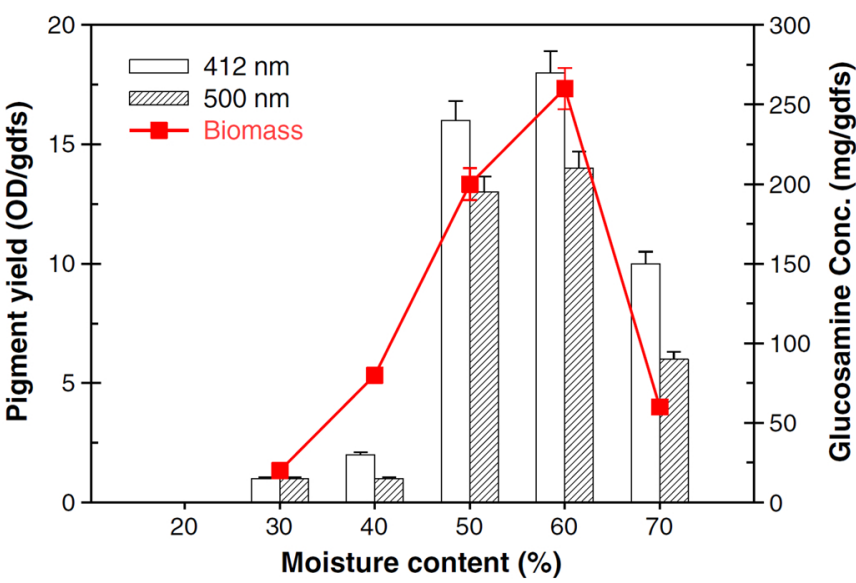

Figure 6. Growth (glucosamine concentration) and pigment yield (optical density 412 and $500 \mathrm{~nm}$ ) of $M$. purpureus in solid state fermentation in response to initial moisture content.

The results of our study indicate the feasibility and applicability of the corn cob, an agricultural byproduct, for SSF production of pigments from $M$. purpureus KACC 42430. The highest yield of the pigments (25.42 OD Units/gdfs) indicates that corn cob powder is an effective substrate for SSF. As mentioned above pulverized corn cob enhance the enzymatic digestibility of $M$. purpureus, resulted in promoting greater pigment production. This enhanced pigment production compared to previously reported substrates. The corn cob is economical and environmentally safe to end users. To our knowledge this is the first report on pigment production using corn cob powder in SSF. Our future work will focus on the chemical nature of the pigments (isochromene derivatives, specifically azaphilone compounds) and the toxin citrinin, a byproduct of the fermentation process.

Acknowledgments - This work was supported by the Korea Research Foundation Grant funded by the Korean Government (KRF-2008313-F00012). The author P.V. is grateful to Chonbuk National University for the postdoctoral grant extension (second term of 2009).

\section{References}

1. Bechtold, T., Mussak, R., Mahmud-Ali, A., Ganglberger, E., and Geissler, D.: Extraction of natural dyes for textile dyeing from coloured plant wastes released from the food and beverage industry, J. Sci. Food Agric., 86, 233-242 (2006).

2. Rai, H., Battacharyya, M. S., Singh, J., Bansal, T. K., Vats, P., and Banerjee, U. C.: Removal of dyes from the effluent of textile and dyestuff manufacturing-industry-A review of emerging techniques with reference to biological treatment, Crit. Rev. Environ. Sci. Technol., 35, 219-238 (2005).

3. Velmurugan, P., Kamala-Kannan, S., Balachandar, V., Lakshmanaperumalsamy, P., Chae, J. C., and Oh, B. T.: Natural pigment extraction from five filamentous fungi for industrial applications and dyeing of leather, Carbohydr. Polym., 79, 262-268 (2010).

4. Santis, D. D., Moresi, M., Gallo, A. M., and Petruccioli, M.: Assessment of the dyeing properties of pigments from Monascus purpureus, J. Chem. Technol. Biotechnol., 80, 1072-1079 (2005).

5. Nagia, F. A. and El-Mohamedy, R. S. R.: Dyeing of wool with natural anthraquinone dyes from Fusarium oxysporum, Dyes Pigm., 75, 550-555 (2007).

6. Babitha, S.: Microbial pigments, pp. 147-150, in: Nigam, P.S. and Pandey, A. (Eds.), Biotechnology for agro-industrial residues utilisation, vol. 5. Springer, Heidelberg (2009).

7. Lin, C. C., Li, T. C., and Lai, M. M.: Efficacy and safety of Monascus purpureus Went rice in subjects with hyperlipidemia, Eur. J. Endocrinol., 153, 679-686 (2005). 
8. Babitha, S., Soccol, C. R., and Pandey, A.: Solid-state fermentation for the production of Monascus pigments from jackfruit seed, Bioresour. Technol., 98, 1554-1560 (2007).

9. Babitha, S., Soccol, C. R., and Pandey, A.: Jackfruit seed-A novel substrate for the production of Monascus pigments through solidstate fermentation, Food Technol. Biotechnol., 44, 465-471 (2006).

10. Nimnoi, P. and Lumyong, S.: Improving solid-state fermentation of Monascus purpureus on agricultural products for pigment production, Food Bioprocess Technol., 4, 1384-1390 (2009).

11. Sakurai, Y., Lee, T. H., and Shiota, H.: On the convenient method of glucosamine estimation in koji, Agric. Biol. Chem., 41, 619-624 (1977).

12. Tseng, Y. Y., Chen, M. T., and Lin, C. F.: Growth, pigment production and protease activity of Monascus purpureus as affected by salt, sodium nitrite, polyphosphate and various sugars, J. Appl. Microbiol., 88, 31-37 (2000).

13. Lin, T. F. and Demain, A.: Formation of water soluble Monascus red pigments by biological and semi synthetic processes, J. Ind. Microbiol. Biotechnol., 9, 173-179 (1992).

14. Chiu, S. W. and Poon, Y. K.: Submerged production of Monascus pigments, Mycologia, 85, 214-218 (1993).

15. Johns, M. R. and Stuart, D. M.: Production of pigments by Monascus purpureus in solid culture, J. Ind. Microbiol. Biotechnol., 8, 23-38 (1991).

16. Srivastava, R. C., Goel, M., and Gulrajani, M. L.: Color gamut of natural dyes on cotton yarns, pp. 288-296, in: Convention on natural dyes, department of textile technology. IIT Delhi, New Delhi (1999).

17. Perumal, K., Stalin, V., Chandrasekarenthiran, S., Sumathi, E., and Saravanakumar, A.: Extraction and characterization of pigment from Sclerotinia sp. and its use in dyeing cotton, Text. Res. J., 79, 1178-1187 (2009).
18. Yongsmith, B., Kitprechavanich, V., Chitrandon, L., Chaisrisook, C., and Budda, N.: Color mutants of Monascus sp. KB9 and their comparative glucoamylase on rice solid culture, J. Mol. Catal. B: Enzym., 10, 263-272 (2000).

19. Domsch, K. H., Gams, W., and Anderson, T. H.: Monascus van Tiegh, pp. 425-426, in: Compendium of soil fungi. Academic Press, London (1980).

20. Carvalho, J. C., Oishi, B. O., Pandey, A., and Soccol, C. R.: Biopigments from Monascus: Strain selection, citrinin production and color stability, Braz. Arch. Biol. Technol., 48, 885-894 (2005).

21. Pandey, A., Soccol, C. R., and Mitchell, D.: New developments in solid state fermentation: I-Bioprocess and products, Process Biochem., 35, 1153-1169 (2000).

22. Chakradhar, D., Javeed, S., and Sattur, A. P.: Studies on the production of nigerloxin using agro-industrial residues by solid-state fermentation, J. Ind. Microbiol. Biotechnol., 36, 1179-1187 (2009).

23. Wang, H. L., Swain, E. W., and Hessel Tine, C. W.: Mass production of Rhizopus oligophorus spores and their application in Tempeh fermentation, J. Food Sci. Technol., 40, 168-170 (1975).

24. Pandey, A.: Recent developments in solid-state fermentation, Process Biochem., 27, 109-116 (1992).

25. Pandey, A.: Solid-state fermentation, Biochem. Eng. J., 13, 81-84 (2003).

26. Carrizales, V. and Rodriguez, H.: Determination of specific growth rate of moulds in semi solid cultures, Biotechnol. Bioeng., 23, 321333 (1981) 